\title{
PROSTATE CANCER: IS IT TIME TO EXPAND THE RESEARCH FOCUS TO EARLY-LIFE EXPOSURES?
}

\author{
Siobhan Sutcliffe ${ }^{1}$ and Graham A. Colditz ${ }^{1}$ \\ ${ }^{1}$ Division of Public Health Sciences and the Alvin J. Siteman Cancer Center, Department of \\ Surgery, Washington University School of Medicine, St. Louis, MO.
}

\section{Preface}

\begin{abstract}
Although the contribution of lifestyle and environment (non-genetic factors) to prostate carcinogenesis is indicated by international variation in prostate cancer occurrence and migration studies, no conclusive modifiable risk factors have been identified to date. One possible reason for this may be the dearth of epidemiological research on exposures experienced early-in-life when the immature prostate may be more susceptible to carcinogenic exposures. Herein, we motivate the study of early-life exposures, describe the small body of early-life research and its associated challenges, and point towards solutions for future research.
\end{abstract}

\section{Introduction}

Prostate cancer $(\mathrm{PCa})$ is the most commonly diagnosed malignancy and the third leading cause of cancer death among men in developed countries. ${ }^{1}$ In the United States alone, an estimated 242,000 will be diagnosed with PCa in 2012 and 28,000 will die from their disease. ${ }^{2}$ Despite its high incidence and mortality, very few risk factors have been identified for PCa beyond increasing age, having a family history of $\mathrm{PCa},{ }^{3}$ having certain genetic polymorphisms or mutations (such as single nucleotide polymorphisms (SNPs) in the 8q24 and $17 \mathrm{q} 12$ chromosomal regions ${ }^{4}$ ), living in a Western nation, and being of African descent. Being of Asian descent is protective for PCa. Migration studies also clearly show that men who migrate from countries with low PCa mortality, such as Japan, assume a higher rate when they move to Western countries with higher mortality. This observation, together with observed increasing PCa mortality rates over calendar time, particularly in countries with traditionally low rates, ${ }^{5}$ strongly suggests that environmental or lifestyle factors contribute to prostate carcinogenesis. However, despite this compelling ecological evidence, as well as decades-worth of observational research and clinical trials of the most promising, suspected dietary protective factors (such as selenium and vitamin $E^{6,7}$ ), no conclusive modifiable environmental or lifestyle risk factors have been identified to date.

We propose that one possible reason for this dearth of modifiable risk factors is the predominant focus of $\mathrm{PCa}$ research on mid- to later-life exposures long after the prostate has developed, whereas earlier-life exposures, such as those that occur during childhood and adolescence when the prostate is still maturing, may be as or more important for PCa risk. In this Perspectives article, we summarize the rationale for, and challenges with, studying these exposures, as well as results from the relatively small number of epidemiological studies of earlier-life exposures (defined in this article as infancy up to age 30). Furthermore, we

Corresponding author: Siobhan Sutcliffe, Division of Public Health Sciences and the Alvin J. Siteman Cancer Center, Department of Surgery, Washington University School of Medicine, 660 S. Euclid Ave., Box 8100, Rm. 208, St. Louis, MO 63110. Tel: (314) 362-3788. Fax: (314) 454-7941. sutcliffes@wudosis.wustl.edu. 
present our vision for how future studies might be carried out to maximize insight into the role of early-life exposures in PCa risk.

\section{Early-life prostate changes}

Aside from gestation, early-life represents the only other time during life when the immature prostate grows and develops. Following birth, the prostate enters into an infantile resting state characterized by continued prostate duct formation, but little change in size. ${ }^{8}$ With the onset of puberty, however, the prostate begins to grow and develop more rapidly and continues to do so until the end of puberty when it reaches approximate adult size and morphology (Figure 1). ${ }^{8,9}$ During these early developmental stages and possibly immediately thereafter, the prostate may be especially susceptible to endogenous and exogenous carcinogenic exposures, ${ }^{10-12}$ as has been demonstrated for other maturing organs, such as the breast. ${ }^{13}$ Women exposed to the Hiroshima and Nagasaki atomic bombs in the first two decades of life were found to have higher risks of breast cancer than those exposed later-in-life, indicating greater susceptibility to breast carcinogens earlier-in-life. ${ }^{14}$ Unfortunately, whether because of an overall lack of association with ionizing radiation ${ }^{14}$ or because of the sparseness of the data for adolescent and young male atomic bomb survivors, ${ }^{15}$ these studies have been less informative for PCa risk. However, data from mathematical models suggest that the initiating genomic alteration for PCa may occur as early as puberty (that is, 14 years of age). ${ }^{16}$

While not necessarily specific to puberty, several additional lines of evidence point towards early development of pre-neoplastic and neoplastic prostate alterations. In men 19-29 years of age, Gardner and Culberson ${ }^{17}$ observed proliferative and/or atrophic lesions in over half of prostate specimens examined. These lesions are increasingly believed to serve as early PCa precursor lesions or markers of an environment conducive to PCa development. ${ }^{18}$ Several other investigators also observed foci of established precursor lesions, high-grade prostatic intraepithelial neoplasia (HGPIN)), and microscopic PCa lesions in a small proportion of men in their 20s (HGPIN: 0.0-7.1\%; PCa: 0.0-3.6\%). ${ }^{19-24}$ These microscopic, autopsy-detected lesions are frequently referred to as histological or latent $\mathrm{PCa}$ (as opposed to clinically manifest cancer) because their future clinical potential is largely unknown, even when detected in older men. ${ }^{25,26}$ Although early-adulthood autopsy studies had too few participants to examine differences in histological lesion prevalence by race, larger studies of other early-life prostate changes (for example, levels of prostate-specific antigen (PSA)), observed expected racial differences: that is, higher serum PSA values for young AfricanAmerican than Caucasian-American men in their 20s, particularly at the upper end of the distribution curve of PSA levels. ${ }^{27,} 28$ PSA is an intraluminal protein that leaks into circulation when the prostate epithelium is disrupted, such as by inflammation ${ }^{29}$ (a possible risk factor for $\mathrm{PCa}^{18}$ ) and by $\mathrm{PCa}$ itself. ${ }^{29}$ Therefore, one possible interpretation of these findings is that changes in the prostate environment related to both future PCa risk, as well as racial disparities in risk, may occur early-in-life.

By the time men reach their 30s, evidence of pre-neoplastic and neoplastic prostate alterations is even more striking. HGPIN and/or histological PCa are found in a greater proportion of men examined (HGPIN: 0.0-11.8\%; PCa: 0.0-28.9\%), ${ }^{19-24,30-35}$ racial disparities in PSA persist, ${ }^{27,} 28,36$ differences in PSA translate into future PCa risk (that is, PCa diagnosis several decades later), ${ }^{28,37}$ and, most importantly, differences in PCa incidence begin to appear by race. ${ }^{38}$ Finally, by the time men reach their 40s, PSA levels are consistently predictive of future PCa risk and mortality $37,39-45$ and racial disparities in PCa mortality (rather than just incidence) become apparent (summarized in Figure 1). ${ }^{38}$ Clearly, factors responsible for these changes - be they genomic, lifestyle-related, or both - must have occurred decades earlier. 


\section{Barriers to early-life epidemiological research}

Despite these compelling reasons for studying early-life exposures, most epidemiological research has focused on mid- to later-life for two major reasons. The first relates to observations made in the 1970s and 1980s of unexpectedly smaller differences in the prevalence of histological PCa in middle- and older-aged men of differing races (for example, African- versus Caucasian-American men) and nationalities (for example, Japanese nationals versus Japanese-American men) relative to the large racial and geographic differences in clinical PCa incidence and mortality; ${ }^{46-48}$ this led to the hypothesis that factors that initiate $\mathrm{PCa}$ are common to all men, whereas factors that promote PCa vary by race and nationality ${ }^{49}$ As PCa promotion probably occurs later-in-life, this hypothesis served to focus research on modifiable risk factors on mid- to later-life.

However, other histological observations contradict this hypothesis. In more recent studies of men from low-PCa risk regions, such as Spain, China, and South-East Asia, expected lower prevalences of histological PCa have been observed than in higher-risk populations. ${ }^{22,}$ 23, 32, 33, 49 Additionally, when histological tumor size and grade are considered, both of which inform future clinical potential, considerably larger differences in the prevalence of histological PCa have been observed by race and nationality in both original and more recent studies. ${ }^{33}, 46,47,50$ Therefore, rather than occurring randomly in all men, initiation or early promotion of histological $\mathrm{PCa}$ - and more importantly, $\mathrm{PCa}$ with greater future potential for progression to clinically relevant disease - may vary by raceand nationality-associated factors, and thus may be modifiable.

The second reason for the dearth of research on early-life modifiable exposures is feasibility. $\mathrm{PCa}$ incidence and mortality are low in men $<50$ years of age and only begin to rise when men reach their 50s and 60s (the median age at diagnosis is 67 years and at death from PCa is 80 years in the United States ${ }^{38}$ ). Therefore, while the time between early-life and PCa diagnosis or death may be as short as two decades, it may also be as long as seven. This long span of time makes cohort studies of directly observed early-life exposures and PCa diagnosis/death essentially impractical, except in unique situations, such as when records from studies of children or adolescents conducted several decades ago can now be linked to cancer registry data. ${ }^{51-55}$ Therefore, most other investigators have instead relied upon recall from older-aged men, raising concerns about the validity of decades-long recall in elderly participants.

\section{Summary of early-life epidemiological studies}

\section{Migration}

Natural experiments, such as exposure to ionizing radiation (described above for atomic bomb survivors) and migration, offer insight into the window of etiological relevance for cancer development. For instance, comparisons of cancer risk between generations of migrants (that is, first versus second or later generations), as well as those who move at different times during their lives (that is, those who move earlier- versus later-in-life) can point towards ages of increased cancer susceptibility. For PCa, although results from studies comparing migrant generations have tended to be conflicting, ${ }^{56-60}$ most, ${ }^{61-66}$ but not all, ${ }^{67,68}$ studies of age at migration — or its complement, duration of residence — have observed increased PCa risk or mortality with younger age at migration to Western countries. While one possible interpretation of these findings is that men who migrate at earlier ages may acculturate to a greater degree, leading to a greater likelihood of PCa screening and detection of occult $\mathrm{PCa}$, another possible interpretation is that age at initial exposure to elements of a higher-risk environment or lifestyle may be important for $\mathrm{PCa}$ risk and mortality. 


\section{Height}

In addition to age at migration, another marker that may inform the window of etiological relevance for PCa risk is height. This measure is believed to be determined by levels of early-life growth factors, such as insulin-like growth factor 1 (IGF-1), which may be influenced by both genetics and early-life modifiable exposures, such as childhood nutrition and infection burden, depending on levels of "environmental adversity". ${ }^{9}$ Although the precise determinants of height are not known, this measure is frequently used as a marker of cumulative early-life exposures because each of these mechanisms must act before attainment of adult height. Height is also an attractive marker from an epidemiological perspective because, contrary to other early-life exposures that must be recalled from adulthood, height can be easily measured in adulthood or reported with excellent validity. ${ }^{70}$ In their recent meta-analysis of height and PCa, MacInnis and English ${ }^{71}$ combined the $^{-}$ results of 39 studies and estimated a positive association between height and PCa risk (that is, taller men had a greater risk of PCa than shorter men; pooled rate ratio (or relative risk, $\mathrm{RR}=1.05,95 \%$ confidence interval (CI): $1.02-1.09$ for each $10 \mathrm{~cm}$ increase in height, Figure 2). This association was stronger for advanced $\mathrm{PCa}(\mathrm{RR}=1.09,95 \% \mathrm{CI}: 0.99-1.21)$ and for cohort studies (RR=1.09, 95\% CI: 1.08-1.11), which, as the authors noted, tended to be conducted before the widespread implementation of PCa screening by PSA when a large proportion of detected cancers presented clinically. Therefore, these results suggest that exposures captured by height may be particularly important for risk of clinically relevant disease. While these findings cannot point conclusively towards early-life as a critical period for PCa susceptibility, as they may also be explained by later-life correlates of height not controlled for in the aforementioned studies (for example, later-life influence of genetic determinants of height, although no overlap between SNPs for height and PCa have yet been detected ${ }^{4},{ }^{72}$ ), these findings still provide support for a role of early-life exposures in prostate carcinogenesis.

\section{Sex hormones}

Based on their role in normal prostate growth, development, and maintenance, as well as the observed regression of advanced $\mathrm{PCa}$ following testosterone suppression, androgens are strongly believed to contribute to PCa development. ${ }^{3}$ However, results from the large number of epidemiological studies of mid- to later-life circulating levels of androgens and PCa risk have been largely null to date. ${ }^{73}$ To our knowledge, only one study has investigated hormone levels earlier-in-life (median age $=34$, range: $20-55$ years) ${ }^{74}$ and closer in time to early-adulthood when androgen levels reach their peak. ${ }^{75,76}$ Although this study observed no association between levels of individual hormones (including testosterone) and PCa risk, it did observe positive associations for ratios of testosterone to estradiol levels among Caucasian- but not African-American participants. ${ }^{74}$

Owing to the long span of time between early-life and PCa diagnosis/death, most other studies have focused on recalled markers of early-life androgen levels, such as severe acne development, ${ }^{77}$ frequency of early-life ejaculatory activity, ${ }^{78-80}$ and early-life lean muscle mass. ${ }^{81}$ With respect to severe acne development, results from the handful of studies conducted to date have been conflicting. ${ }^{54,82-84}$ In contrast, those from the small number of studies of early-life ejaculatory activity (which includes sexual intercourse, but may be more likely to capture masturbation and nocturnal emission) have tended to be null to protective (that is, men with higher frequencies of ejaculation had similar or lower risk of PCa than men with lower frequencies). ${ }^{85-88}$ However, it is possible that ejaculation frequency may be a better marker of frequency of prostate duct clearance - which has been proposed to protect against $\mathrm{PCa}$ by reducing the contact time of accumulated carcinogens with prostate epithelial cells ${ }^{89}$ - than hormone levels. Finally, only two studies have investigated early- 
life lean muscle mass (calculated from weight and height rather than more sophisticated methods) in relation to PCa with conflicting findings. 82,90

The remaining few studies of relative body size in peri-puberty ${ }^{91-93}$ or puberty, ${ }^{12,94}$ and the larger number of studies of body mass index (BMI) in early-adulthood (from 18-30 years $)^{63,91,95-97}$ are more difficult to interpret because they may potentially have captured several different factors. These include early-life lean muscle mass (which is related to greater androgen levels), ${ }^{81}$ early-life adiposity (which has been proposed to delay puberty in boys ${ }^{98-100}$ and to lower pubertal androgen levels), ${ }^{100}$ or a combination of both. ${ }^{95}$ Robinson and colleagues ${ }^{95}$ commented on this possibility in their recent meta-analysis of 16 studies of early-adulthood BMI and PCa, in which they estimated a non-significant positive association for BMI (pooled RR=1.06, 95\% CI: 0.99-1.14 for each 5-unit increase in BMI). These authors noted that their estimated linear association between early-adulthood BMI and PCa might, in fact, have combined two distinct associations: a positive association between early-adulthood BMI as a marker of lean mass in the lower, non-obese range of BMI; and a null or protective association between early-adulthood BMI as a marker of fat mass in the higher, obese range of BMI (Figure 3). ${ }^{95}$ Indeed, protective or suggestively protective associations were observed for greater early-life adiposity with advanced PCa risk in two American studies with sufficient numbers of overweight or obese boys and young men to address this question. ${ }^{98,100}$ Therefore, it is possible that stronger positive associations may be observed between BMI as a marker of lean mass and $\mathrm{PCa}$ in future studies that distinguish adipose from non-adipose young men. Although promotion of lower early-life lean mass and higher fat mass is not a viable PCa prevention strategy, further study of this reasonably well-recalled early-life exposure (correlation $=0.80-0.93$ for validity of recall in middle- and older-aged men) ${ }^{70,101-103}$ is still important for its insight into timing and mechanisms of PCa development, as these may possibly lead to chemoprevention opportunities (that is, drugs targeted towards identified molecular pathways).

\section{Timing of puberty}

In addition to levels of hormones, the length of time that the prostate is exposed to high levels of androgens may also be important for cancer risk. For instance, earlier age at onset of puberty increases risk of breast cancer in women, ${ }^{13}$ presumably by extending the length of time that breast epithelial cells are exposed to high levels of cyclical sex steroid hormones. By a similar reasoning, earlier age at onset of puberty may also increase risk of PCa in men. ${ }^{82,92}$ However, in contrast to women, for whom age at onset of puberty can be ascertained by a single measure (that is, menarche) with reasonable accuracy of recall, ${ }^{104}$ no single measure exists for men. Furthermore, for the multiple measures that do exist (for example, age at first pubic or facial hair growth, and age at growth spurt), the accuracy of recall tends to be lower than for other early-life exposures (correlation $=0.18-0.58$ for validity of mid-life recall ${ }^{104}$ and $0.73-0.83$ for reproducibility of early-life recall ${ }^{105}$ ). Not surprisingly, therefore, results from studies of recalled timing of puberty and PCa have tended to be mixed and generally inconclusive. ${ }^{11,12,19,82,83,85,92,106-110}$ Although future research into this biologically plausible hypothesis is certainly warranted, better methods for ascertaining age at onset of puberty in men are needed. It should also be recognized that, as for early-adulthood BMI, the value of further study is limited to insight into the timing and mechanisms of PCa development and possible chemoprevention strategies. Altering pubertal timing - for instance, through early-life obesity — is not a viable PCa prevention strategy.

\section{Sexual activity and infections}

Early-life sexual activity is also closely related to androgen levels and timing of puberty. However, as it may be more likely to capture the likelihood and timing of exposure to sexually transmitted and transmissible infectious agents (Figure 4), which have been 
proposed to increase PCa risk through inflammatory and oncogenic mechanisms, ${ }^{111}$ we are considering it separately. Additionally, in contrast to most previously discussed potential early-life risk factors, sexual activity and exposure to sexually transmissible agents is modifiable and thus any conclusive findings can be translated into prevention strategies. In their meta-analysis of sexual behavior and PCa, Dennis and Dawson ${ }^{112}$ pooled the results of several case-control studies of sexually related factors and $\mathrm{PCa}$, and estimated a positive association for age at first sexual intercourse (pooled odds ratio $(\mathrm{OR})=1.08$, 95\% CI: 1.02 1.15 for each five year decrease in age at first sexual intercourse based on 12 studies) and a non-significant, positive association for frequency of early-life sexual intercourse (OR=1.14, 95\% CI: $0.98-1.31$ for 3 versus < 1 time/week based on three studies). For circumcision, which may reduce the risk of acquiring sexually transmitted or transmissible infections, such as HIV infection, ${ }^{113}$ protective or suggestive protective associations were also observed in several, but not all, ${ }^{11,19,114,115}$ case-control studies of circumcision and $\mathrm{PCa},{ }^{116-118}$ and studies comparing PCa prevalence and incidence by religion as a marker of circumcision status. ${ }^{119,120}$ Thus together, these findings provide support for a role of early-life exposure to sexually transmissible infections in prostate carcinogenesis.

In contrast to these findings, those for recalled history of well-known, frequently symptomatic sexually transmitted infections (STIs, such as gonorrhea, which is commonly acquired in adolescence and early-adulthood ${ }^{121}$ ) have been less conclusive. While results for case-control studies have tended to be positive (pooled OR=1.4, 95\% CI: 1.2-1.7 based on 17 studies $^{112}$ ), those for cohort studies were largely null. ${ }^{111}$ As case-control studies require participants to recall exposures after PCa diagnosis, whereas cohort studies ascertain exposures before diagnosis, these discrepancies raise the possibility of recall bias (that is, cases may have been more likely to report their STI history truthfully than controls). This concern is also relevant for studies of age at first sexual intercourse and frequency of earlylife sexual activity. However, as protective findings were observed for circumcision status, which should be less influenced by recall bias, as well as for early-life ejaculation frequency, which should be subject to the same recall influences as early-life sexual activity, recall bias may be less of a concern. Positive associations are also beginning to be observed for additional less well-studied and frequently asymptomatic STIs, such as Trichomonas vaginalis $^{111}$ and mycoplasma infections. ${ }^{122-124}$

Finally, while not typically investigated in relation to solid tumor risk, at least four studies have examined childhood infections and infection-related procedures in relation to PCa. ${ }^{83,94,106,125}$ These include studies of rheumatic fever, tonsillectomy, appendectomy, measles, mumps, and other several other infections. Although findings for most of these infections and procedures were null, positive associations were observed for rheumatic fever ${ }^{106,} 125$ and tonsillectomy, ${ }^{125}$ both of which are, interestingly, related to Streptococcus pyogenes. Rheumatic fever is a now rare complication of $S$. pyogenes infection and tonsillectomy is performed frequently for $S$. pyogenes tonsillitis. These unusual findings are difficult to explain but perhaps, similar to one mechanism proposed for severe acne and $\mathrm{PCa},{ }^{126}$ they may imply altered susceptibility or immune sensitivity to infection, which could be relevant for PCa in the case of prostate infection. Although Streptococcus species are not typically considered to be prostate pathogens, they have been detected in prostate specimens, ${ }^{127}$ as well as in the urethra following the onset of sexual activity, ${ }^{128}$ suggesting that they may be transmitted by sexual activity and thus could contribute to a sexually transmissible etiology of PCa. Alternatively, these findings may point towards a more general role for immune sensitivity to infection or other prostatic stimuli in prostate carcinogenesis. 


\section{Physical activity}

As alluded to earlier for sexual activity and STIs, an attractive feature of studying exposures such as early-life physical activity is the ability to intervene on these exposures if they are found to be associated with later PCa risk. Unfortunately, however, only "limited"129 evidence of an association has been observed between physical activity (typically later-life or lifetime activity) and PCa in the relatively large number of epidemiological studies conducted to date. Mostly null or occasionally suggestive protective associations have also been observed in the smaller number of studies of early-life physical activity when activity was recalled approximately 4-6 decades later-in-life. ${ }^{12,63,94,130-138}$ Although positive findings were observed for greater physical activity in two studies of college students ("major [varsity] athletes," 51 and students who reported $\geq 5$ hours/week of physical activity ${ }^{52}$ ), these findings may potentially have been complicated by confounding factors associated with both high levels of college physical activity and possibly increased PCa risk, such as earlier age at growth spurt, greater meat consumption, or greater body build, although adjustment for height and/or weight did not change these findings. ${ }^{51,52}$ Thus, overall, these findings do not support a protective role for early-life physical activity in PCa development.

Despite these largely null findings, early-life physical activity may warrant further study for two reasons: it is modifiable and has benefits beyond PCa; and slightly stronger protective associations were observed for other aspects of physical activity measured with less recall time and greater reproducibility than early-life physical activity (that is, mid- to laterlife $\mathrm{e}^{139-141}$ and occupational physical activity ${ }^{139,142}$ ), raising the possibility that, with better measurement, early-life physical activity might also protect against PCa to some degree. ${ }^{139}$ Inclusion of better estimates of early-life physical activity into overall lifetime measures might also provide a clearer picture of the role of physical activity in prostate carcinogenesis.

\section{Diet}

Based on the results of both migration studies and ecological comparisons of national food consumption data with PCa mortality, diet, and more specifically, a Western diet, is strongly believed to contribute to PCa risk. ${ }^{3}$ Despite this strong belief, however, remarkably few studies $(n=7)$ have examined early-life diet in relation to PCa, especially compared to the extensive literature on mid- to later-life diet (over several hundred analyses). Moreover, of the few early-life studies that have been conducted, several relied on recall of diet 4-6 decades earlier-in-life, ${ }^{12,143-145}$ which is considerably less accurate than recall over fewer decades; ${ }^{146}$ few examined nutrients/foods suspected to be associated with PCa risk (Figure 5); few examined or published the results of more than one nutrient or aspect of diet; $55,143,147,148$ and only a maximum of three considered the same nutrient (i.e., fat ${ }^{12,} 143$ and total dairy/milk intake $\left.{ }^{12,55,144}\right)$. Otherwise, each study examined separate nutrients or aspects of diet in relation to $\mathrm{PCa}$ (for example, vegetarian diet, ${ }^{147}$ and total energy, ${ }^{148}$ coffee, tea, alcohol, ${ }^{125}$ margarine, eggs, fish, meat/sausage, liver, carrots, cookies/crackers/ pastries, ${ }^{12}$ oatmeal, and rye bread ${ }^{145}$ intake). Even considering studies of early-life sun exposure, which helps to produce vitamin D in the skin but can also be obtained through diet, only an additional seven studies have been performed. ${ }^{149-155}$ Therefore, although findings from many of these studies were null or conflicting, the literature is clearly still too small and varied to draw sound conclusions about early-life diet at this time. However, given the strong rationale for studying diet and $\mathrm{PCa}$, and the strong potential for primary $\mathrm{PCa}$ prevention, more research on early-life diet is clearly needed. 


\section{Perspectives}

In summary, despite compelling reasons for studying early-life risk factors for PCa, much of the extensive PCa epidemiological literature has focused on mid- to later-life exposures with few, if any, conclusive, modifiable risk factors identified to date. In contrast, relatively few studies have examined exposures earlier-in-life and, of these, many were limited by low exposure recall accuracy (for example, studies of timing of puberty, and early-life physical activity and diet). However, promising findings for other early-life exposures or markers of these exposures that have been examined in a greater number of studies and/or with greater accuracy (that is, migration status, height, early-adulthood body size, and early-life sexual activity) provide support for an early-life etiology for PCa. With better measurement, additional insight into early-life mechanisms of carcinogenesis and opportunities for $\mathrm{PCa}$ prevention may be uncovered.

Given these promising observations, but lingering difficulties of studying early-life exposures for such a late-onset cancer, how can the field move forward? While one obvious and definitive option would be to perform cohort studies of males followed from childhood until PCa diagnosis or death, the large expense and time necessary to conduct these studies will limit their number. Therefore, we propose several alternate near- and longer-term strategies instead (Figure 6).

\section{Near-term strategies}

One immediate or near-term strategy is to analyze data from continually maturing cohort studies of children, adolescents, or young adults assembled several decades ago, or to link cross-sectional or cohort data collected decades ago with cancer or death registries (for example, Boyd Orr cohort, ${ }^{55}$ Third Harvard Growth, ${ }^{156}$ Manitoba Follow-up, ${ }^{157}$ Harvard Alumni Health, ${ }^{125}$ and Glasgow Alumni ${ }^{54}$ studies). These resources are, however, finite and tend to have smaller sample sizes than necessary to study PCa as an outcome. Therefore, combined analyses across many of these studies may be required for adequate power. Another near-term option is to reduce the length of recall from old-age to at least middle-age in epidemiological studies of early-life risk factors, as the accuracy of recall typically improves with reduced recall time. ${ }^{103,141,146}$ For instance, rather than conducting casecontrol studies of all newly diagnosed eligible PCa cases (for whom the median age at diagnosis in the United States is 67 years ${ }^{38}$ ), case-control studies including only cases below a certain age (for example, 55 years) could be performed to increase the accuracy of recall of early-life exposures. Restriction of cohort analyses to younger men at exposure assessment could also be performed in existing cohort studies to improve recall accuracy.

The above-described near-term strategies apply to both modifiable exposures, such as diet, as well as markers of early-life sex hormone levels and timing of puberty for their insight into the timing and mechanisms of PCa development. However, another largely-untapped potential source of insight into these aspects of $\mathrm{PCa}$ development is germline genetic variation. Although this variation is present from birth, examination of the timing of expression of genes in which PCa-related SNPs and mutations have been found may point towards time periods of increased relevance for prostate carcinogenesis. For instance, if a particular candidate gene is only expressed early- or later-in-life in the prostate, this finding might suggest the importance of that particular time period for prostate carcinogenesis because the variant or mutated gene product would only act at that time. This information would also be useful for informing when "environmental" exposures should be assessed in studies of gene by environment interactions.

Finally, in addition to human studies, animal models may also provide insight into early-life etiologies of PCa. Although generalizability to humans is always a consideration, animal 
studies are advantageous because of their experimental design and shorter time frame to completion than human cohort studies. To our knowledge, only a few such animal studies have been conducted to date. However, findings from these studies have been promising with a greater observed influence of pubertal exposures (for example, testosterone administration and dietary restriction) than adult exposures on PCa-related outcomes. ${ }^{158-160}$ These initial promising findings clearly warrant further animal model research.

\section{Long-term strategies}

Most of the near-term strategies described above can be implemented with existing resources or methodologies. However, new methodologies that reduce the length of time required to study early-life risk factors for PCa should also be developed. For instance, intermediate or surrogate markers of future PCa risk should be studied so that wellcharacterized young boys/men would only need to be followed for a relatively short period of time for the development of intermediate or surrogate markers of risk rather than for decades for the development of PCa. This strategy has been used successfully for breast cancer by using benign breast disease as a marker of future breast cancer risk. ${ }^{161}$

Additionally, irrespective of their possible use as intermediate or surrogate markers of PCa, early-life histological PCa lesions should also be investigated further for their relevance to later clinically manifest disease and potential insight into oncogenic mechanisms.

A final consideration for future studies of early-life PCa etiology is the focus of exposures investigated. While much can be learned about the timing and underlying biological mechanisms of PCa from studies of non-modifiable factors, such as sex hormone levels and timing of puberty, the utility of these factors for PCa prevention is largely limited to possible chemoprevention strategies. On the other hand, studies of modifiable factors, such as diet, physical activity, and sexual activity or sexually transmissible infections, have the potential to lead to readily implementable and less expensive primary PCa prevention strategies (for example, dietary modification, greater physical activity, and vaccination) if they are found to be associated with PCa risk. In particular, greater emphasis should be placed on diet in future studies, as it is strongly suspected to influence PCa risk but has not been examined in any great detail in early-life epidemiological studies conducted to date.

None of the strategies outlined above is simple. However, given the high morbidity and mortality of PCa, particularly in Western countries; the dearth of identified modifiable risk factors to date; and the decades-worth of epidemiological research on mid- to later-life exposures, expanding the research focus to early-life exposures may hold the key to uncovering the etiology of $\mathrm{PCa}$ and pathways for prevention.

\section{Acknowledgments}

We thank Drs. Gerald L. Andriole, Angelo M. De Marzo, Elizabeth A. Platz, and Catherine G. Sutcliffe for valuable discussion related to this manuscript; Dr. Peter Humphrey for generous provision of prostate histologic images; and Amy Ostendorf for assistance preparing figures.

This manuscript was funded by the Barnes-Jewish Hospital Foundation. It makes use of data obtained from the Radiation Effects Research Foundation (RERF), Hiroshima and Nagasaki, Japan. RERF is a private, non-profit foundation funded by the Japanese Ministry of Health, Labour and Welfare and the U.S. Department of Energy, the latter through the National Academy of Sciences. The conclusions in this report are those of the authors and do not necessarily reflect the scientific judgment of RERF or its funding agencies. 


\section{Glossary box}

\section{Case-control study}

Cohort study

\section{Confounding \\ factor (or confounder)}

\section{Correlate \\ Ecological evidence}

Exposure

Marker
An observational epidemiological study of people with a disease of interest (cases) and those without (controls). A link between the suspected risk factor and the disease is suggested when the frequency of that risk factor is significantly different between cases and controls.

An epidemiological study of people exposed or not exposed to a suspected risk factor who are subsequently observed over time for the development of the disease of interest. A link between the suspected risk factor and the disease is suggested when the exposed and unexposed participants have a significantly different frequency of future development of the disease.

A variable that is associated with both the suspected risk factor and the disease, but that is not caused by the suspected risk factor. Confounders can distort the association between the suspected risk factor and the disease. For example, alcohol consumption may appear to increase the risk of lung cancer because of confounding by cigarette smoking, a variable that is associated with, but not caused by, alcohol consumption and that is associated with an increased risk of lung cancer.

A variable that is related statistically, but not necessarily causally, to another variable. For example, cigarette smoking is a correlate of alcohol consumption.

Evidence derived from studies in which the units of analysis are populations or groups of people (for example, a country) rather than individuals. Ecological evidence is susceptible to ecologic fallacy, whereby the relation observed between variables on an aggregate level may not reflect the relation between variables on an individual level.

A variable whose causal effect is to be estimated. Examples of exposures are environmental and lifestyle factors, socioeconomic and working conditions, medical treatments, and genetic traits.

A variable (such as height) that may be causally or non-causally related to another variable of interest (such as levels of early-life growth factors). The marker can be useful for estimating the variable of interest if that variable cannot be measured or assessed directly.

Definitions adapted from reference ${ }^{162}$.

\section{References}

1. American Cancer Society. Global Cancer Facts \& Figures. 2nd Edition. Atlanta, GA: American Cancer Society; 2011.

2. Siegel R, Naishadham D, Jemal A. Cancer statistics, 2012. CA Cancer J Clin. 2012; 62:10-29. [PubMed: 22237781]

3. Gronberg H. Prostate cancer epidemiology. Lancet. 2003; 361:859-864. [PubMed: 12642065]

4. Kim ST, et al. Prostate cancer risk-associated variants reported from genome-wide association studies: meta-analysis and their contribution to genetic Variation. Prostate. 2010; 70:1729-1738. [PubMed: 20564319]

5. Hsing AW, Tsao L, Devesa SS. International trends and patterns of prostate cancer incidence and mortality. Int J Cancer. 2000; 85:60-67. [PubMed: 10585584] 
6. Lippman SM, et al. Effect of selenium and vitamin E on risk of prostate cancer and other cancers: the Selenium and Vitamin E Cancer Prevention Trial (SELECT). JAMA. 2009; 301:39-51. [PubMed: 19066370]

7. Gaziano JM, et al. Vitamins $\mathrm{E}$ and $\mathrm{C}$ in the prevention of prostate and total cancer in men: the Physicians' Health Study II randomized controlled trial. JAMA. 2009; 301:52-62. [PubMed: 19066368]

8. Humphrey, PA. Prostate pathology 2-29. Chicago: American Society for Clinical Pathology; 2003.

9. Marshall, WA.; Tanner, JM. Human Growth: Postnatal growth, neurobiology. Falkner, F.; Tanner, JM., editors. New York: Plennum; 1986. p. 171-209.

10. Ross R, et al. Serum testosterone levels in healthy young black and white men. J Natl Cancer Inst. 1986; 76:45-48. [PubMed: 3455741]

11. Rotkin ID. Studies in the epidemiology of prostatic cancer: expanded sampling. Cancer Treat Rep. 1977; 61:173-180. [PubMed: 68821]

12. Andersson SO, et al. Early life risk factors for prostate cancer: a population-based case-control study in Sweden. Cancer Epidemiol Biomarkers Prev. 1995; 4:187-192. [PubMed: 7606192]

13. Chodosh LA, et al. Mammary gland development, reproductive history, and breast cancer risk. Cancer Res. 1999; 59:1765s-1771s. discussion 1771s-1772s.

14. United Nations Scientific Committee on the Effects of Atomic Radiation. UNSCEAR 2006 Report. Vol. Volume 1. New York: United Nations; 2008. Effects of ionizing radiation.

15. Radiation Effects Research Foundation. A Cooperative Japan-US Research Organization. Accessed at: http://www.rerf.or.jp/library/dl_e/lss14.html on 30 July, 2012

16. Diamandis EP, Yu H. Does prostate cancer start at puberty? J Clin Lab Anal. 1996; 10:468-469. [PubMed: 8951622]

17. Gardner WA Jr, Culberson DE. Atrophy and proliferation in the young adult prostate. J Urol. 1987; 137:53-56. [PubMed: 2432282]

18. De Marzo AM, et al. Inflammation in prostate carcinogenesis. Nat Rev Cancer. 2007; 7:256-269. [PubMed: 17384581]

19. Jackson MA, et al. Factors involved in the high incidence of prostatic cancer among American blacks. Prog Clin Biol Res. 1981; 53:111-132. [PubMed: 7465581]

20. Sakr WA, Haas GP, Cassin BF, Pontes JE, Crissman JD. The frequency of carcinoma and intraepithelial neoplasia of the prostate in young male patients. J Urol. 1993; 150:379-385. [PubMed: 8326560]

21. Sakr WA, et al. High grade prostatic intraepithelial neoplasia (HGPIN) and prostatic adenocarcinoma between the ages of 20-69: an autopsy study of 249 cases. In Vivo. 1994; 8:439443. [PubMed: 7803731]

22. Gu FL, Xia TL, Kong XT. Preliminary study of the frequency of benign prostatic hyperplasia and prostatic cancer in China. Urology. 1994; 44:688-691. [PubMed: 7526525]

23. Sanchez-Chapado M, Olmedilla G, Cabeza M, Donat E, Ruiz A. Prevalence of prostate cancer and prostatic intraepithelial neoplasia in Caucasian Mediterranean males: an autopsy study. Prostate. 2003; 54:238-247. [PubMed: 12518329]

24. Yin M, Bastacky S, Chandran U, Becich MJ, Dhir R. Prevalence of incidental prostate cancer in the general population: a study of healthy organ donors. J Urol. 2008; 179:892-895. discussion 895. [PubMed: 18207193]

25. Humphrey, PA. Prostate pathology. Chicago: American Society for Clinical Pathology; 2003. p. 226-257.

26. Nomura AM, Kolonel LN. Prostate cancer: a current perspective. Epidemiol Rev. 1991; 13:200227. [PubMed: 1765112]

27. Preston DM, et al. Prostate-specific antigen levels in young white and black men 20 to 45 years old. Urology. 2000; 56:812-816. [PubMed: 11068308]

28. Whittemore AS, Cirillo PM, Feldman D, Cohn BA. Prostate specific antigen levels in young adulthood predict prostate cancer risk: results from a cohort of Black and White Americans. J Urol. 2005; 174:872-876. discussion 876. [PubMed: 16093978] 
29. Oesterling JE. Prostate specific antigen: a critical assessment of the most useful tumor marker for adenocarcinoma of the prostate. J Urol. 1991; 145:907-923. [PubMed: 1707989]

30. Lee YS, Shanmugaratnam K. Latent prostate carcinoma in Singapore Chinese. Singapore Med J. 1972; 13:1-6. [PubMed: 5031950]

31. Shiraishi $\mathrm{T}$, et al. The frequency of latent prostatic carcinoma in young males: the Japanese experience. In Vivo. 1994; 8:445-447. [PubMed: 7803732]

32. Miller GJ, Pfister S, Xia T, Zhau HE. Latent carcinomas of the prostate in males from Beijing. J Urol. 1994; 151:A204.

33. Magi-Galluzzi C, et al. The prevalence and extent of autopsy prostate cancer is less in South East Asian men than North American men. J Urol. 2004; 171:118.

34. Soos G, et al. The prevalence of prostate carcinoma and its precursor in Hungary: an autopsy study. Eur Urol. 2005; 48:739-744. [PubMed: 16203079]

35. Stamatiou K, Alevizos A, Agapitos E, Sofras F. Incidence of impalpable carcinoma of the prostate and of non-malignant and precarcinomatous lesions in Greek male population: an autopsy study. Prostate. 2006; 66:1319-1328. [PubMed: 16688747]

36. Sutcliffe $\mathrm{S}$, et al. Prostate-specific antigen concentration in young men: new estimates and review of the literature. BJU Int. 2012

37. Lilja $\mathrm{H}$, et al. Prediction of significant prostate cancer diagnosed 20 to 30 years later with a single measure of prostate-specific antigen at or before age 50. Cancer. 2011; 117:1210-1219. [PubMed: 20960520]

38. Howlader, N., et al. SEER Cancer Statistics Review, 1975-2009 (Vintage 2009 Populations). Bethesda, MD: National Cancer Institute; http://seer.cancer.gov/csr/1975_2009_pops09/, based on November 2011 SEER data submission, posted to the SEER web site, April 2012

39. Fang J, et al. Low levels of prostate-specific antigen predict long-term risk of prostate cancer: results from the Baltimore Longitudinal Study of Aging. Urology. 2001; 58:411-416. [PubMed: 11549490]

40. Antenor JA, Han M, Roehl KA, Nadler RB, Catalona WJ. Relationship between initial prostate specific antigen level and subsequent prostate cancer detection in a longitudinal screening study. $\mathrm{J}$ Urol. 2004; 172:90-93. [PubMed: 15201744]

41. Connolly D, Black A, Gavin A, Keane PF, Murray LJ. Baseline prostate-specific antigen level and risk of prostate cancer and prostate-specific mortality: diagnosis is dependent on the intensity of investigation. Cancer Epidemiol Biomarkers Prev. 2008; 17:271-278. [PubMed: 18250343]

42. Holmstrom B, et al. Prostate specific antigen for early detection of prostate cancer: longitudinal study. BMJ. 2009; 339:b3537. [PubMed: 19778969]

43. Tang P, et al. Initial prostate specific antigen $1.5 \mathrm{ng} / \mathrm{ml}$ or greater in men 50 years old or younger predicts higher prostate cancer risk. J Urol. 2010; 183:946-950. [PubMed: 20083275]

44. Orsted DD, Nordestgaard BG, Jensen GB, Schnohr P, Bojesen SE. Prostate-specific antigen and long-term prediction of prostate cancer incidence and mortality in the general population. Eur Urol. 2011; 61:865-874. [PubMed: 22104593]

45. Kuller LH, Thomas A, Grandits G, Neaton JD. Elevated prostate-specific antigen levels up to 25 years prior to death from prostate cancer. Cancer Epidemiol Biomarkers Prev. 2004; 13:373-377. [PubMed: 15006911]

46. Breslow N, et al. Latent carcinoma of prostate at autopsy in seven areas The International Agency for Research on Cancer, Lyons, France. Int J Cancer. 1977; 20:680-688. [PubMed: 924691]

47. Yatani R, et al. Geographic pathology of latent prostatic carcinoma. Int J Cancer. 1982; 29:611616. [PubMed: 7107064]

48. Billis A. Latent carcinoma and atypical lesions of prostate An autopsy study. Urology. 1986; 28:324-329. [PubMed: 2429422]

49. Miller, GJ. in Advanced therapy of prostate disease. Resnick, MI.; Thompson, IM., editors. Hamilton: B. C. Decker, Inc; 2000. p. 18-27.

50. Whittemore AS, Keller JB, Betensky R. Low-grade, latent prostate cancer volume: predictor of clinical cancer incidence? J Natl Cancer Inst. 1991; 83:1231-1235. [PubMed: 1870149] 
51. Polednak AP. College athletics, body size, and cancer mortality. Cancer. 1976; 38:382-387. [PubMed: 947530]

52. Whittemore AS, Paffenbarger RS Jr, Anderson K, Lee JE. Early precursors of urogenital cancers in former college men. J Urol. 1984; 132:1256-1261. [PubMed: 6502830]

53. Engeland A, Tretli S, Bjorge T. Height, body mass index, and prostate cancer: a follow-up of 950000 Norwegian men. Br J Cancer. 2003; 89:1237-1242. [PubMed: 14520453]

54. Galobardes B, Davey Smith G, Jeffreys M, Kinra S, McCarron P. Acne in adolescence and causespecific mortality: lower coronary heart disease but higher prostate cancer mortality: the Glasgow Alumni Cohort Study. Am J Epidemiol. 2005; 161:1094-1101. [PubMed: 15937017]

55. van der Pols JC, et al. Childhood dairy intake and adult cancer risk: 65-y follow-up of the Boyd Orr cohort. Am J Clin Nutr. 2007; 86:1722-1729. [PubMed: 18065592]

56. Locke FB, King H. Cancer mortality risk among Japanese in the United States. J Natl Cancer Inst. 1980; 65:1149-1156. [PubMed: 6933246]

57. King H, Locke FB. Cancer mortality among Chinese in the United States. J Natl Cancer Inst. 1980; 65:1141-1148. [PubMed: 6933245]

58. Kolonel LN. Cancer patterns of four ethnic groups in Hawaii. J Natl Cancer Inst. 1980; 65:1127_ 1139. [PubMed: 6933244]

59. Severson RK, Nomura AM, Grove JS, Stemmermann GN. A prospective study of demographics, diet, and prostate cancer among men of Japanese ancestry in Hawaii. Cancer Res. 1989; 49:18571860. [PubMed: 2924323]

60. Singh GK, Miller BA. Health, life expectancy, and mortality patterns among immigrant populations in the United States. Can J Public Health. 2004; 95:I14-I21. [PubMed: 15191127]

61. Parkin DM, et al. Cancer in Jewish migrants to Israel. Int J Cancer. 1990; 45:614-621. [PubMed: 1691150]

62. Tyczynski J, Tarkowski W, Parkin DM, Zatonski W. Cancer mortality among Polish migrants to Australia. Eur J Cancer. 1994; 30A:478-484. [PubMed: 8018406]

63. Whittemore AS, et al. Prostate cancer in relation to diet, physical activity, and body size in blacks, whites, and Asians in the United States and Canada. J Natl Cancer Inst. 1995; 87:652-661. [PubMed: 7752270]

64. McCredie M, Williams S, Coates M. Cancer mortality in East and Southeast Asian migrants to New South Wales, Australia, 1975-1995. Br J Cancer. 1999; 79:1277-1282. [PubMed: 10098772]

65. Beiki O, Ekbom A, Allebeck P, Moradi T. Risk of prostate cancer among Swedish-born and foreign-born men in Sweden, 1961-2004. Int J Cancer. 2009; 124:1941-1953. [PubMed: 19107943]

66. Armstrong, BK.; Woodings, TL.; Stenhouse, NS.; McCall, MG. Perth, Australia: NH \& MRC Research Unit in Epidemiology and Preventive Medicine, Raine Medical Statistics Unit Department of Medicine The University of Western Australia; 1983. Mortality from cancer in migrants to Australia, 1962 to 1971.

67. Shimizu H, et al. Cancers of the prostate and breast among Japanese and white immigrants in Los Angeles County. Br J Cancer. 1991; 63:963-966. [PubMed: 2069852]

68. McCredie M, Williams S, Coates M. Cancer mortality in migrants from the British Isles and continental Europe to New South Wales, Australia, 1975-1995. Int J Cancer. 1999; 83:179-185. [PubMed: 10471524]

69. Gunnell D, et al. Height, leg length, and cancer risk: a systematic review. Epidemiol Rev. 2001; 23:313-342. [PubMed: 12192740]

70. Norgan NG, Cameron N. The accuracy of body weight and height recall in middle-aged men. Int J Obes Relat Metab Disord. 2000; 24:1695-1698. [PubMed: 11126226]

71. MacInnis RJ, English DR. Body size and composition and prostate cancer risk: systematic review and meta-regression analysis. Cancer Causes Control. 2006; 17:989-1003. [PubMed: 16933050]

72. Lango Allen $\mathrm{H}$, et al. Hundreds of variants clustered in genomic loci and biological pathways affect human height. Nature. 2010; 467:832-838. [PubMed: 20881960] 
73. Roddam AW, Allen NE, Appleby P, Key TJ. Endogenous sex hormones and prostate cancer: a collaborative analysis of 18 prospective studies. J Natl Cancer Inst. 2008; 100:170-183. [PubMed: 18230794]

74. Tsai CJ, et al. Sex steroid hormones in young manhood and the risk of subsequent prostate cancer: a longitudinal study in African-Americans and Caucasians (United States). Cancer Causes Control. 2006; 17:1237-1244. [PubMed: 17111254]

75. Gupta D, Rager K, Attanasio A, Klemm W, Eichner M. Sex steroid hormones during multiphase pubertal developments. J Steroid Biochem. 1975; 6:859-868. [PubMed: 170460]

76. Gapstur SM, et al. Serum androgen concentrations in young men: a longitudinal analysis of associations with age, obesity race. The CARDIA male hormone study Cancer Epidemiol Biomarkers Prev. 2002; 11:1041-1047.

77. Lolis MS, Bowe WP, Shalita AR. Acne and systemic disease. Med Clin North Am. 2009; 93:1161-1181. [PubMed: 19932324]

78. Udry JR, Billy JO, Morris NM, Groff TR, Raj MH. Serum androgenic hormones motivate sexual behavior in adolescent boys. Fertil Steril. 1985; 43:90-94. [PubMed: 4038388]

79. Knussmann R, Christiansen K, Couwenbergs C. Relations between sex hormone levels and sexual behavior in men. Arch Sex Behav. 1986; 15:429-445. [PubMed: 3789906]

80. Mantzoros CS, Georgiadis EI, Trichopoulos D. Contribution of dihydrotestosterone to male sexual behaviour. BMJ. 1995; 310:1289-1291. [PubMed: 7773040]

81. Herbst KL, Bhasin S. Testosterone action on skeletal muscle. Curr Opin Clin Nutr Metab Care. 2004; 7:271-277. [PubMed: 15075918]

82. Giles GG, et al. Early growth, adult body size and prostate cancer risk. Int J Cancer. 2003; 103:241-245. [PubMed: 12455039]

83. Lightfoot N, et al. Medical history, sexual, and maturational factors and prostate cancer risk. Ann Epidemiol. 2004; 14:655-662. [PubMed: 15380796]

84. Sutcliffe S, Giovannucci E, Isaacs WB, Willett WC, Platz EA. Acne and risk of prostate cancer. Int J Cancer. 2007; 121:2688-2692. [PubMed: 17724724]

85. Oishi K, et al. A case-control study of prostatic cancer in Kyoto, Japan: sexual risk factors. Prostate. 1990; 17:269-279. [PubMed: 2251222]

86. Hsieh CC, et al. Risk factors for prostate cancer: a case-control study in Greece. Int J Cancer. 1999; 80:699-703. [PubMed: 10048970]

87. Giles GG, et al. Sexual factors and prostate cancer. BJU Int. 2003; 92:211-216. [PubMed: 12887469]

88. Leitzmann MF, Platz EA, Stampfer MJ, Willett WC, Giovannucci E. Ejaculation frequency and subsequent risk of prostate cancer. JAMA. 2004; 291:1578-1586. [PubMed: 15069045]

89. Isaacs JT. Prostatic structure and function in relation to the etiology of prostatic cancer. Prostate. 1983; 4:351-366. [PubMed: 6866850]

90. Liu X, Rybicki BA, Casey G, Witte JS. Relationship between body size and prostate cancer in a sibling based case-control study. J Urol. 2005; 174:2169-2173. [PubMed: 16280757]

91. Dal Maso L, et al. Prostate cancer and body size at different ages: an Italian multicentre casecontrol study. Br J Cancer. 2004; 90:2176-2180. [PubMed: 15150581]

92. Barba M, et al. Indicators of sexual and somatic development and adolescent body size in relation to prostate cancer risk: results from a case-control study. Urology. 2008; 72:183-187. [PubMed: 18280559]

93. Jeffreys M, Smith GD, Martin RM, Frankel S, Gunnell D. Childhood body mass index and later cancer risk: a 50-year follow-up of the Boyd Orr study. Int J Cancer. 2004; 112:348-351. [PubMed: 15352051]

94. Ilic M, Vlajinac H, Marinkovic J. Case-control study of risk factors for prostate cancer. $\mathrm{Br}$ J Cancer. 1996; 74:1682-1686. [PubMed: 8932356]

95. Robinson WR, Poole C, Godley PA. Systematic review of prostate cancer's association with body size in childhood and young adulthood. Cancer Causes Control. 2008; 19:793-803. [PubMed: 18347923] 
96. Cox B, Sneyd MJ, Paul C, Skegg DC. Risk factors for prostate cancer: A national case-control study. Int J Cancer. 2006; 119:1690-1694. [PubMed: 16646073]

97. Bassett JK, et al. Weight change and prostate cancer incidence and mortality. Int J Cancer. 2012; 131:1711-1719. [PubMed: 22213024]

98. Robinson WR, Stevens J, Gammon MD, John EM. Obesity before age 30 years and risk of advanced prostate cancer. Am J Epidemiol. 2005; 161:1107-1114. [PubMed: 15937019]

99. Freedland SJ, Platz EA. Obesity and prostate cancer: making sense out of apparently conflicting data. Epidemiol Rev. 2007; 29:88-97. [PubMed: 17478439]

100. Giovannucci E, Rimm EB, Stampfer MJ, Colditz GA, Willett WC. Height, body weight, and risk of prostate cancer. Cancer Epidemiol Biomarkers Prev. 1997; 6:557-563. [PubMed: 9264267]

101. Rhoads GG, Kagan A. The relation of coronary disease, stroke, and mortality to weight in youth and in middle age. Lancet. 1983; 1:492-495. [PubMed: 6131209]

102. Casey VA, et al. Long-term memory of body weight and past weight satisfaction: a longitudinal follow-up study. Am J Clin Nutr. 1991; 53:1493-1498. [PubMed: 2035478]

103. Tamakoshi K, et al. The accuracy of long-term recall of past body weight in Japanese adult men. Int J Obes Relat Metab Disord. 2003; 27:247-252. [PubMed: 12587006]

104. Casey VA, et al. Accuracy of recall by middle-aged participants in a longitudinal study of their body size and indices of maturation earlier in life. Ann Hum Biol. 1991; 18:155-166. [PubMed: 2024949]

105. Gilger JW, Geary DC, Eisele LM. Reliability and validity of retrospective self-reports of the age of pubertal onset using twin, sibling, and college student data. Adolescence. 1991; 26:41-53. [PubMed: 2048480]

106. Mishina T, Watanabe H, Araki H, Nakao M. Epidemiological study of prostatic cancer by matched-pair analysis. Prostate. 1985; 6:423-436. [PubMed: 4088954]

107. Fincham SM, Hill GB, Hanson J, Wijayasinghe C. Epidemiology of prostatic cancer: a casecontrol study. Prostate. 1990; 17:189-206. [PubMed: 2235728]

108. Hayes RB, et al. Physical characteristics and factors related to sexual development and behaviour and the risk for prostatic cancer. Eur J Cancer Prev. 1992; 1:239-245. [PubMed: 1467769]

109. Habel LA, Van Den Eeden SK, Friedman GD. Body size, age at shaving initiation, and prostate cancer in a large, multiracial cohort. Prostate. 2000; 43:136-143. [PubMed: 10754529]

110. Rosenblatt KA, Wicklund KG, Stanford JL. Sexual factors and the risk of prostate cancer. Am J Epidemiol. 2001; 153:1152-1158. [PubMed: 11415949]

111. Sutcliffe S. Sexually transmitted infections and risk of prostate cancer: review of historical and emerging hypotheses. Future Oncol. 2010; 6:1289-1311. [PubMed: 20799875]

112. Dennis LK, Dawson DV. Meta-analysis of measures of sexual activity and prostate cancer. Epidemiology. 2002; 13:72-79. [PubMed: 11805589]

113. Larke N. Male circumcision, HIV and sexually transmitted infections: a review. Br J Nurs. 2010; 19:629-634. [PubMed: 20622758]

114. Wynder EL, Mabuchi K, Whitmore WF Jr. Epidemiology of cancer of the prostate. Cancer. 1971; 28:344-360. [PubMed: 5109447]

115. Mandel JS, Schuman LM. Sexual factors and prostatic cancer: results from a case-control study. J Gerontol. 1987; 42:259-264. [PubMed: 3553301]

116. Wright JL, Lin DW, Stanford JL. Circumcision and the risk of prostate cancer. Cancer. 2012; 118:4437-4443. [PubMed: 22411189]

117. Ewings P, Bowie C. A case-control study of cancer of the prostate in Somerset and east Devon. Br J Cancer. 1996; 74:661-666. [PubMed: 8761387]

118. Ross RK, Shimizu H, Paganini-Hill A, Honda G, Henderson BE. Case-control studies of prostate cancer in blacks and whites in southern California. J Natl Cancer Inst. 1987; 78:869-874. [PubMed: 3471995]

119. Ravich A, Ravich RA. Prophylaxis of cancer of the prostate, penis, and cervix by circumcision. N Y State J Med. 1951; 51:1519-1520. [PubMed: 14853120]

120. Apt A. Circumcision and prostatic cancer. Acta Med Scand. 1965; 178:493-504. [PubMed: 5891277] 
121. Centers for Disease Control and Prevention. Sexually Transmitted Disease Surveillance 2010. Atlanta, GA: U.S. Department of Health and Human Services; 2011.

122. Urbanek C, et al. Detection of antibodies directed at M. hyorhinis p37 in the serum of men with newly diagnosed prostate cancer. BMC Cancer. 2011; 11:233. [PubMed: 21663671]

123. Barykova YA, et al. Association of Mycoplasma hominis infection with prostate cancer. Oncotarget. 2011; 2:289-297. [PubMed: 21471611]

124. Hrbacek J, et al. Serum antibodies against genitourinary infectious agents in prostate cancer and benign prostate hyperplasia patients: a case-control study. BMC Cancer. 2011; 11:53. [PubMed: 21291519]

125. Whittemore AS, Paffenbarger RS Jr, Anderson K, Lee JE. Early precursors of site-specific cancers in college men and women. J Natl Cancer Inst. 1985; 74:43-51. [PubMed: 3855486]

126. Shannon BA, Garrett KL, Cohen RJ. Links between Propionibacterium acnes and prostate cancer. Future Oncol. 2006; 2:225-232. [PubMed: 16563091]

127. Sfanos KS, et al. A molecular analysis of prokaryotic and viral DNA sequences in prostate tissue from patients with prostate cancer indicates the presence of multiple and diverse microorganisms. Prostate. 2008; 68:306-320. [PubMed: 18163428]

128. Chambers CV, et al. Microflora of the urethra in adolescent boys: relationships to sexual activity and nongonococcal urethritis. J Pediatr. 1987; 110:314-321. [PubMed: 3100755]

129. IARC Handbooks of Cancer Prevention. Weight control and physical activity. Vol. Vol 6. Lyon, France: IARC Press; 2002.

130. Villeneuve PJ, Johnson KC, Kreiger N, Mao Y. Risk factors for prostate cancer: results from the Canadian National Enhanced Cancer Surveillance System The Canadian Cancer Registries Epidemiology Research Group. Cancer Causes Control. 1999; 10:355-367. [PubMed: 10530605]

131. Lacey JV Jr, et al. Prostate cancer, benign prostatic hyperplasia and physical activity in Shanghai, China. Int J Epidemiol. 2001; 30:341-39. [PubMed: 11369740]

132. Friedenreich CM, McGregor SE, Courneya KS, Angyalfi SJ, Elliott FG. Case-control study of lifetime total physical activity and prostate cancer risk. Am J Epidemiol. 2004; 159:740-749. [PubMed: 15051583]

133. Pierotti B, et al. Lifetime physical activity and prostate cancer risk. Int J Cancer. 2005; 114:639642. [PubMed: 15609333]

134. Littman AJ, Kristal AR, White E. Recreational physical activity and prostate cancer risk (United States). Cancer Causes Control. 2006; 17:831-841. [PubMed: 16783611]

135. Darlington GA, Kreiger N, Lightfoot N, Purdham J, Sass-Kortsak A. Prostate cancer risk and diet, recreational physical activity and cigarette smoking. Chronic Dis Can. 2007; 27:145-153. [PubMed: 17623560]

136. Wiklund F, et al. Lifetime total physical activity and prostate cancer risk: a population-based case-control study in Sweden. Eur J Epidemiol. 2008; 23:739-746. [PubMed: 18931922]

137. Krishnadasan A, Kennedy N, Zhao Y, Morgenstern H, Ritz B. Nested case-control study of occupational physical activity and prostate cancer among workers using a job exposure matrix. Cancer Causes Control. 2008; 19:107-114. [PubMed: 18064535]

138. Moore SC, et al. Age-specific physical activity and prostate cancer risk among white men and black men. Cancer. 2009; 115:5060-5070. [PubMed: 19645029]

139. Liu Y, et al. Does physical activity reduce the risk of prostate cancer? A systematic review and meta-analysis. Eur Urol. 2011; 60:1029-1044. [PubMed: 21802197]

140. Kriska AM, et al. The assessment of historical physical activity and its relation to adult bone parameters. Am J Epidemiol. 1988; 127:1053-1063. [PubMed: 3358406]

141. Chasan-Taber L, et al. Reproducibility of a self-administered lifetime physical activity questionnaire among female college alumnae. Am J Epidemiol. 2002; 155:282-289. [PubMed: 11821254]

142. Friedenreich CM, Courneya KS, Bryant HE. The lifetime total physical activity questionnaire: development and reliability. Med Sci Sports Exerc. 1998; 30:266-274. [PubMed: 9502356] 
143. Slattery ML, Schumacher MC, West DW, Robison LM, French TK. Food-consumption trends between adolescent and adult years and subsequent risk of prostate cancer. Am J Clin Nutr. 1990; 52:752-757. [PubMed: 2403069]

144. Torfadottir JE, et al. Milk intake in early life and risk of advanced prostate cancer. Am J Epidemiol. 2012; 175:144-153. [PubMed: 22190107]

145. Torfadottir JE, et al. Rye bread consumption in early life and reduced risk of advanced prostate cancer. Cancer Causes Control. 2012; 23:941-950. [PubMed: 22527172]

146. Chavarro JE, et al. Validity of adolescent diet recall 48 years later. Am J Epidemiol. 2009; 170:1563-1570. [PubMed: 19923106]

147. Mills PK, Beeson WL, Phillips RL, Fraser GE. Cohort study of diet, lifestyle, and prostate cancer in Adventist men. Cancer. 1989; 64:598-604. [PubMed: 2743254]

148. Dirx MJ, van den Brandt PA, Goldbohm RA, Lumey LH. Energy restriction in childhood and adolescence and risk of prostate cancer: results from the Netherlands Cohort Study. Am J Epidemiol. 2001; 154:530-537. [PubMed: 11549558]

149. Luscombe CJ, et al. Exposure to ultraviolet radiation: association with susceptibility and age at presentation with prostate cancer. Lancet. 2001; 358:641-642. [PubMed: 11530156]

150. Bodiwala D, et al. Prostate cancer risk and exposure to ultraviolet radiation: further support for the protective effect of sunlight. Cancer Lett. 2003; 192:145-149. [PubMed: 12668278]

151. Gilbert R, et al. Life course sun exposure and risk of prostate cancer: population-based nested case-control study and meta-analysis. Int J Cancer. 2009; 125:1414-1423. [PubMed: 19444909]

152. John EM, Schwartz GG, Koo J, Van Den Berg D, Ingles SA. Sun exposure, vitamin D receptor gene polymorphisms, and risk of advanced prostate cancer. Cancer Res. 2005; 65:5470-5479. [PubMed: 15958597]

153. Nair-Shalliker V, et al. Sun exposure may increase risk of prostate cancer in the high UV environment of New South Wales Australia A case-control study. Int J Cancer. 2011

154. Freedman DM, Dosemeci M, McGlynn K. Sunlight and mortality from breast, ovarian, colon, prostate, and non-melanoma skin cancer: a composite death certificate based case-control study. Occup Environ Med. 2002; 59:257-262. [PubMed: 11934953]

155. John EM, Koo J, Schwartz GG. Sun exposure and prostate cancer risk: evidence for a protective effect of early-life exposure. Cancer Epidemiol Biomarkers Prev. 2007; 16:1283-1286. [PubMed: 17548698]

156. Must A, Phillips SM, Naumova EN. Occurrence and timing of childhood overweight and mortality: findings from the Third Harvard Growth Study. J Pediatr. 2012; 160:743-750. [PubMed: 22183448]

157. Mathewson FA, Brereton CC, Keltie WA, Paul GI. The Univeristy of Manitoba Follow-up Study: A Prospective Investigation of Cardiovascular Disease I General Description--Mortality and Incidence of Coronary Heart Disease. Can Med Assoc J. 1965; 92:947-953. [PubMed: 14285286]

158. Angelsen A, Falkmer S, Sandvik AK, Waldum HL. Pre- and postnatal testosterone administration induces proliferative epithelial lesions with neuroendocrine differentiation in the dorsal lobe of the rat prostate. Prostate. 1999; 40:65-75. [PubMed: 10386466]

159. Suttie A, et al. A grading scheme for the assessment of proliferative lesions of the mouse prostate in the TRAMP model. Toxicol Pathol. 2003; 31:31-38. [PubMed: 12597447]

160. Suttie AW, et al. An investigation of the effects of late-onset dietary restriction on prostate cancer development in the TRAMP mouse. Toxicol Pathol. 2005; 33:386-397. [PubMed: 15805078]

161. Berkey CS, et al. Prospective study of adolescent alcohol consumption and risk of benign breast disease in young women. Pediatrics. 2010; 125:e1081-e1087. [PubMed: 20385629]

162. Porta, M.; Greenland, S.; Last, JM., editors. A dictionary of epidemiology. Fifth edition. Oxford: Oxford University Press; 2008.

163. Nakayama M, et al. Hypermethylation of the human glutathione S-transferase-pi gene (GSTP1) $\mathrm{CpG}$ island is present in a subset of proliferative inflammatory atrophy lesions but not in normal or hyperplastic epithelium of the prostate: a detailed study using laser-capture microdissection. Am J Pathol. 2003; 163:923-933. [PubMed: 12937133] 
164. Humphrey, PA. Prostate pathology 182-217. Chicago: American Society for Clinical Pathology; 2003.

165. Hurst R, et al. Selenium and prostate cancer: systematic review and meta-analysis. Am J Clin Nutr. 2012; 96:111-122. [PubMed: 22648711]

166. Huncharek M, Muscat J, Kupelnick B. Dairy products, dietary calcium and vitamin D intake as risk factors for prostate cancer: a meta-analysis of 26,769 cases from 45 observational studies. Nutr Cancer. 2008; 60:421-441. [PubMed: 18584476]

167. Wei MY, Giovannucci EL. Lycopene, Tomato Products, and Prostate Cancer Incidence: A Review and Reassessment in the PSA Screening Era. J Oncol. 2012; 2012:271063. [PubMed: 22690215]

168. Alexander DD, Mink PJ, Cushing CA, Sceurman B. A review and meta-analysis of prospective studies of red and processed meat intake and prostate cancer. Nutr J. 2010; 9:50. [PubMed: 21044319]

169. Simon JA, Chen YH, Bent S. The relation of alpha-linolenic acid to the risk of prostate cancer: a systematic review and meta-analysis. Am J Clin Nutr. 2009; 89:1558S-1564S. [PubMed: 19321563] 


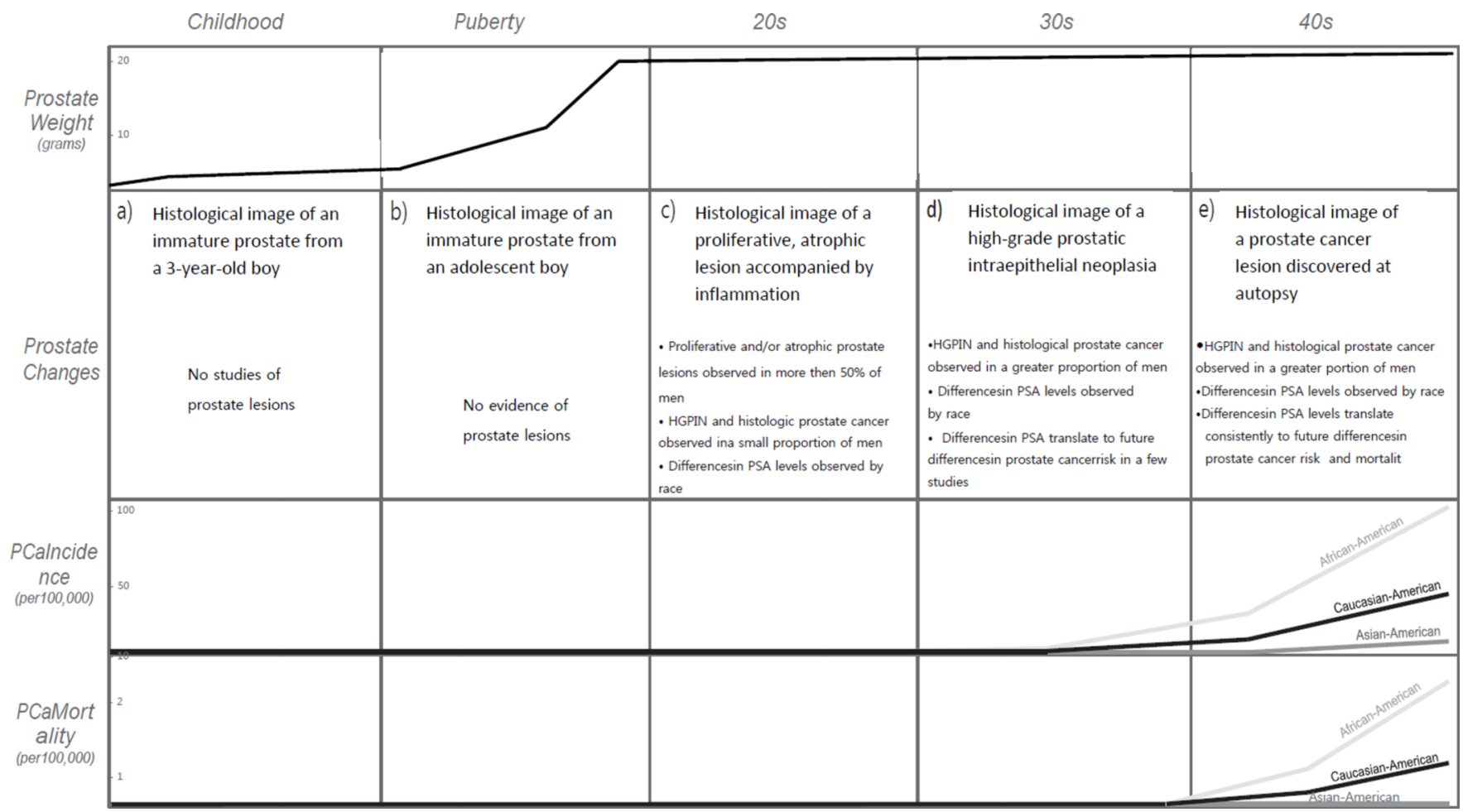

Figure 1. Prostate development and pathology across the life course

HGPIN=high-grade prostatic intraepithelial neoplasia; $\mathrm{PCa}=$ prostate cancer; $\mathrm{PSA}=$ prostatespecific antigen

During childhood, although prostate ducts continue to develop, the immature prostate changes little in size. Figure a) is a histological image of an immature prostate from a three year old boy. Figure is reproduced from ref $^{8}$. With the onset of puberty, the prostate begins to grow and develop more rapidly and continues to do so until the end of puberty when it reaches approximate adult size and morphology. Figure b) is a histological image of a prostate from an adolescent boy. Figure is courtesy of Dr. Peter A. Humphrey. By 19-29 years of age, evidence of pre-neoplastic and neoplastic prostate alterations can be observed. Proliferative and/or atrophic lesions similar to those proposed as early PCa precursor lesions have been observed in over half of men examined. Figure c) is a histological image of a proliferative, atrophic lesion accompanied by inflammation. Figure is reproduced from ref ${ }^{163}$. Foci of established precursor lesions, HGPIN, and microscopic, histological PCa have also been observed in a small proportion of men. In addition to histological changes, differences in levels of PSA - an intraluminal protein that leaks into circulation when the prostate epithelium is disrupted, such as by inflammation (a possible risk factor for $\mathrm{PCa}$ ) and by PCa itself - have been observed in young men by race. That is, higher PSA levels have been observed in young African-American than Caucasian-American men in their 20s. By 30-39 years of age, evidence of pre-neoplastic and neoplastic changes is even more striking. HGPIN and/or histological PCa have been found in a greater proportion of men examined, racial disparities in PSA persist, differences in PSA translate into future PCa risk (that is, $\mathrm{PCa}$ diagnosis several decades later), and differences in PCa incidence begin to appear by race. Figure d) is a histological image of an HGPIN lesion. Figure is reproduced from ref ${ }^{164}$. Finally, in men 40-49 years of age, HGPIN and/or histological PCa have been found in a greater proportion of men examined, racial disparities in PSA continue to persist, PSA levels are consistently predictive of future $\mathrm{PCa}$ risk and mortality, and racial disparities in 
PCa mortality (rather than just incidence) begin to appear. Figure e) is a histological image of a PCa lesion discovered at autopsy. Figure is reproduced from ref 25. 
Figure 2. Meta-analysis of studies of the relationship between height and prostate cancer (PCa) risk

$\mathrm{n}=$ number of PCa cases; $\mathrm{N}=$ total number of men (cohort studies) or number of controls (case-control studies). All pooled rate ratios (or relative risks, RRs) were calculated using maximally adjusted RRs and random effects methodology.

Based on the results of 39 epidemiological studies, MacInnis and English ${ }^{71}$ estimated an overall positive association between height and PCa risk (that is, taller men had a greater risk of $\mathrm{PCa}$ than shorter men, pooled $\mathrm{RR}=1.05,95 \%$ confidence interval $(\mathrm{CI}): 1.02-1.09$ for each $10 \mathrm{~cm}$ increase in height). This association was stronger for cohort studies $(\mathrm{RR}=1.09$, 95\% CI: 1.08-1.11) than for case-control studies ( $\mathrm{RR}=1.00,95 \% \mathrm{CI}$ : 0.93-1.07) and for advanced $\mathrm{PCa}(\mathrm{RR}=1.09,95 \% \mathrm{CI}$ : 0.99-1.21) than for localized PCa (RR=1.06, 95\% CI: 1.00-1.12). As cohort studies were more likely to have been conducted before the widespread implementation of PCa screening by prostate-specific antigen when a large proportion of detected cancers presented clinically, both of these findings suggest that height may be important for risk of clinically relevant disease. Figure is reproduced from ref ${ }^{71}$. The references for each study included in the meta-analysis can be found in the original article. 


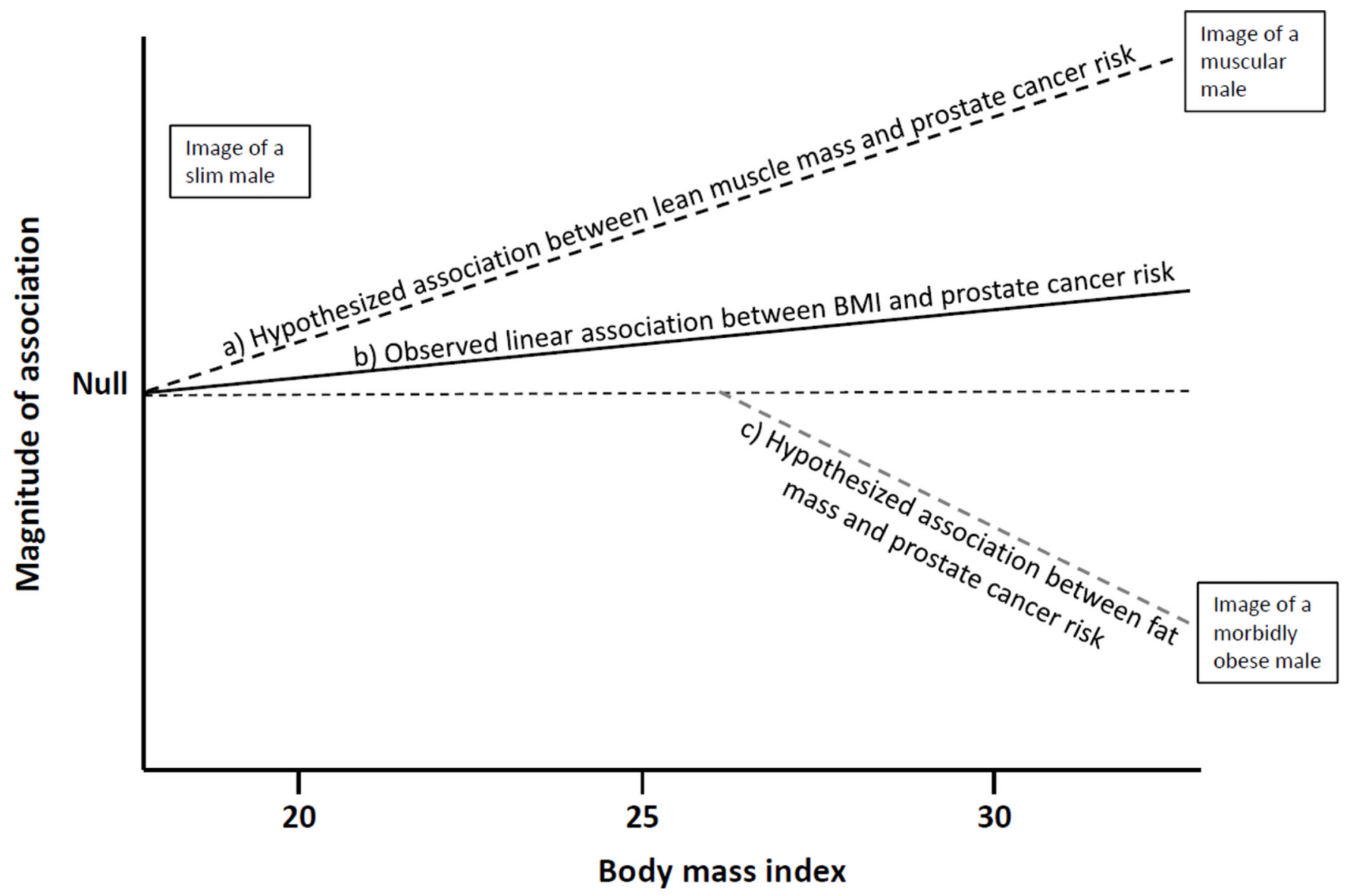

Figure 3. Conceptual plot of the association between early-adulthood body mass index (BMI) and prostate cancer $(\mathrm{PCa})$ risk

BMI may increase as a result of both greater lean muscle mass or greater fat mass.

Therefore, as described by Robinson and colleagues, ${ }^{95}$ the estimated linear association between early-adulthood $\mathrm{BMI}$ and $\mathrm{PCa}((\mathrm{b})$ pooled relative risk $=1.06,95 \%$ confidence interval: $0.99-1.14$ based on 16 studies) may reflect the combination of two distinct associations: a positive association between increasing lean muscle mass as a marker of greater early-life androgen levels and $\mathrm{PCa}(\mathrm{a})$; and a protective association between increasing fat mass as a marker of delayed puberty and lower early-life androgen levels (or higher estrogen levels) and PCa (c). Distinction of adipose from non-adipose young men in future studies may elucidate these two hypothesized associations. 
Figure 4. Mean number of bacterial isolates in 16 non-sexually active and 42 sexually active adolescent boys of similar age

GNC=gram-negative cocci; GNR=gram-negative rods; GPC=gram-positive cocci; $\mathrm{GPR}=$ gram-positive rods.

Bacteria were cultured from urethral swabs of 16 non-sexually active and 42 sexually active American adolescent boys (mean age $=16.0$ and 16.8 years, respectively). Sexually active boys had a greater mean total number of bacterial isolates than non-sexually active boys, including a greater mean number of aerobic gram-negative rod isolates, anaerobic grampositive cocci isolates, and possibly anaerobic gram-negative rod isolates. These findings suggest that sexual activity exposes the urethra to a wide range of new bacterial species. ${ }^{128}$ Figure is reproduced from ref ${ }^{128}$. 


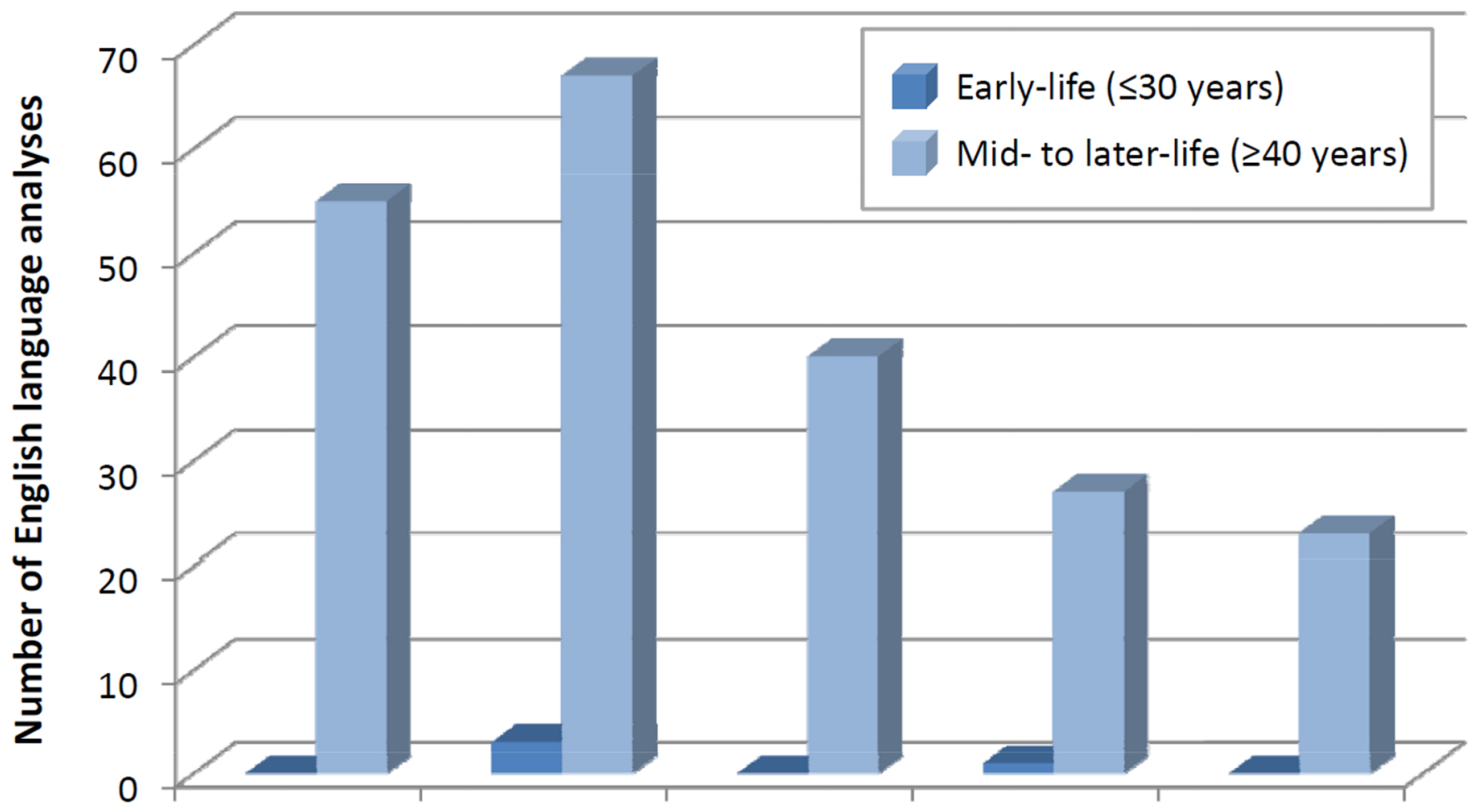

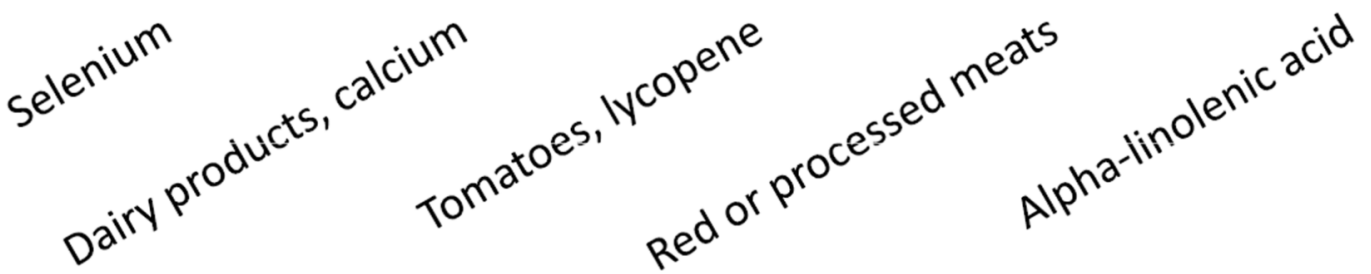

Figure 5. Number of epidemiological analyses of selected suspected dietary risk factors and PCa stratified by timing of consumption: early-life versus mid- to later-life $\mathrm{PCa}=$ prostate cancer

The number of English language epidemiological analyses of selected suspected dietary risk factors and PCa are presented by timing of consumption: early-life versus mid- to later-life. Whereas many analyses have been performed to investigate mid- to later-life suspected dietary risk factors, only a maximum of three (for dairy products and/or calcium) have been performed to investigate these factors earlier-in-life. The number of analyses performed for each suspected dietary risk factor was obtained by retrieving the latest meta-analysis or review article for each dietary factor ${ }^{165-169}$ and then adding to this number analyses published since the date of the respective meta-analysis and October, 2012. Additional analyses were obtained by searching Pubmed with the following search terms: selenium, dairy, milk, calcium, tomato, lycopene, meat, alpha-linolenic acid, fatty acid, and prostate cancer. 


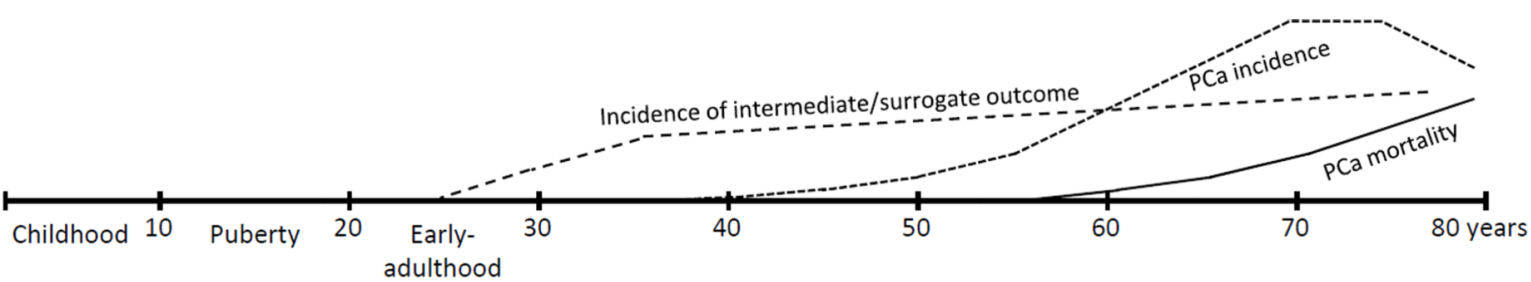

a)

Older existing study populations

Image of a man

Image of a mouse b)

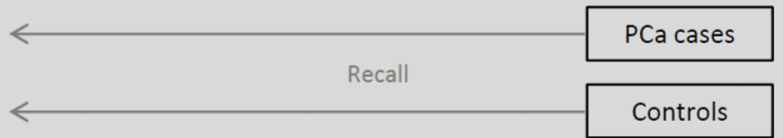

c)

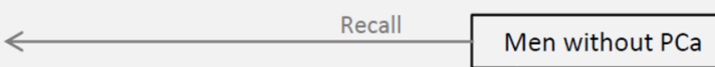

Follow for PCa diagnosis/death

d)

Follow for

intermediate/surrogate

Boys/adolescents/young men outcome $\longrightarrow$

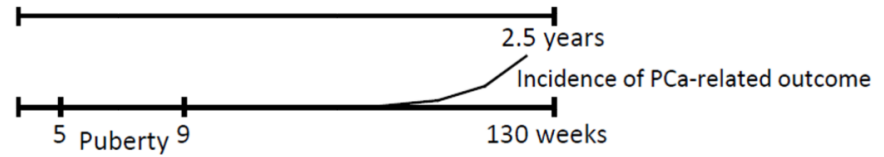

e)

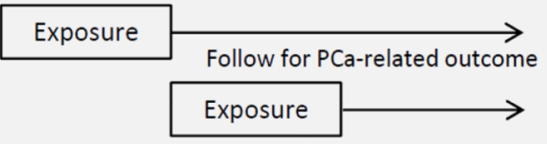

Figure 6. Future directions for early-life etiological studies of prostate cancer

a) One immediate or near-term strategy is to analyze data from continually maturing cohort studies of children, adolescents, or young adults assembled several decades ago or to link cross-sectional or cohort data collected decades ago with cancer or death registries. Another near-term option is to reduce the length of recall from old-age to at least middle-age in epidemiological studies of early-life risk factors, as the accuracy of recall typically improves with reduced recall time. b) For instance, rather than conducting case-control studies of all newly diagnosed eligible prostate cancer (PCa) cases, case-control studies including only cases below a certain age (for example, 55 years) could be performed to increase the accuracy of recall of early-life exposures. c) As another example, cohort analyses restricted to younger men at exposure assessment could also be performed in existing cohort studies. d) As a longer-term strategy, intermediate or surrogate markers of future PCa risk should be studied so that well-characterized young boys/men would only need to be followed for the development of intermediate or surrogate markers of risk rather than for the development of PCa. e) In addition to human studies, animal models can also be used to study early-life etiologies of PCa. For instance, early post-neonatal or pubertal exposures could be compared to adult exposures in appropriate animal models. 